\title{
EXPERIMENTAL INVESTIGATION ON DUAL FUEL ENGINE PERFORMANCE AND EMISSION CHARACTERISTICS USING DIESEL AND MOSAMBI PEEL PYRO OIL WITH OXYGEN CONCENTRATION
}

\author{
VENKATESAN. $\mathrm{K}^{1} \&$ RITHANYA. $\mathrm{S}^{2}$ \\ ${ }^{1}$ Associate Professor, Department of Mechanical Engineering, Koneru Lakshmaiah Education Foundation, \\ Vaddeswaram, Guntur, Andhra Pradesh, India \\ ${ }^{2}$ PG Scholar, Department of Mechanical Engineering, Koneru Lakshmaiah Education Foundation, \\ Vaddeswaram, Guntur, Andhra Pradesh, India
}

\begin{abstract}
Dual fuel engines use two fuels i.e. primary and pilot fuel and have many advantages. By using biofuels, which are abundant and environment friendly as the pilot fuel, emissions can be diminished to a great extent with high efficiency. An experiment is conducted on a single cylinder, Direct Injection diesel engine in Dual fuel mode using $90 \%$ diesel and $10 \%$ mosambi peel pyro oil with varying amounts of oxygen concentration. The results are then compared to the performance parameters of a diesel engine like Brake Thermal Efficiency, Brake Specific Fuel Consumption, HC, CO, $\mathrm{NO}_{x}$ and Smoke emissions. The experimental results revealed that BTE increased by 5.35\%, BSFC decreased to $27.03 \%$ and the exhaust emissions $\mathrm{HC}, \mathrm{CO}$ and Smoke decreased to $14.61 \%, 47.98 \%$ and $17.94 \%$ respectively and NOx emissions increased to about $5.63 \%$ when compared to that of diesel fuel operation.

KEYWORDS: Dual fuel Engine, Pyro Oil, Oxygen Enrichment, Performance, Emissions \& Combustion characteristics
\end{abstract}

Received: Jan 26, 2020; Accepted: Feb 16, 2020; Published: May 05, 2020; Paper Id.: IJMPERDJUN202032

\section{INTRODUCTION}

Dual fuel engine from the name itself can be seen that it uses two fuels, both gaseous and liquid. One is called primary fuel and the other one is called pilot fuel. Generally, pilot fuel is the source of ignition. Dual fuel Engines have many advantages over other type of engines such as; they could switch to gaseous fuel if there is no liquid fuel available i.e., the engine can switch to single fuel mode instantly without any interruption in the engine operation. These engines have been commonly used in Marine industry. Dual fuel engines are getting popularised in many parts of the world like North America, Australia, and are being tested in European countries. Dual fuel engine technology has been implemented in various cities in the USA mostly in heavy duty tractors, trucks etc. This can also be used in well drilling, hydraulic pumps etc.

Diesel engines are widely used because they use a cost-effective fuel and has high energy density.When the diesel fuel burns as a stoichiometric mixture, high temperature is achieved which helps in the oxidation of nitrogen. Due to this, $\mathrm{NO}_{\mathrm{x}}$ emissions emitted are high in diesel engines. Here, the biofuels come into the play. It has been popular that Biofuels are both eco- friendly and a lot more cost effective than diesel. When the fuel mixture is lean, it can result in a slower combustion rate and hence the tendency of knocking is high. To eliminate this, mixing the fuel with oxygen which is also known as oxygen enrichment of the fuel, is adapted. Advantages of adding oxygen to the fuel are stable combustion, improved thermal efficiency, and better fuel economy. Oxygen 
enrichment also reduces the ignition delay and thereby quickens the combustion rate. Oxygen enrichment would cause the $\mathrm{HC}$ and $\mathrm{CO}$ emissions to be lessened but $\mathrm{NO}_{\mathrm{x}}$ emissions are increased to some extent.

Addition of oxygen can be done in two ways i.e. the downright oxygen enrichment to the intake charge, or utilizingoxygenated fuels. From the research, it was found that the downright enrichment of intake charge is more impactful which induces a faster burn rate and stable combustion, hence increasing BTE and peak cylinder pressure.

Factors like premixing of air, Exhaust Gas Recirculation (EGR), blending alcohols with the oxygenated fuels are also considered to reduce the exhaust emissions like smoke, $\mathrm{HC}, \mathrm{CO}$ etc. The characteristics like fuel evaporation, endothermic and pyrolysis process can get affected by the amount of oxygen available and ambient temperature. Premixing of air initiates a quicker heat release and therefore reducing the ignition delay. But premixing has its own limitations like increase in fuel atomization rate, decrease in air density which leads to a drastic decrease of volumetric efficiency. If EGR can be employed, it would cause an increase in fuel vaporisation and also increasing possibilities of $\mathrm{NO}_{\mathrm{x}}$ emissions. Hence, the use of oxygenated fuels or oxygen enrichment can be preferred due to its several advantages.

By using Biofuels in dual fuel engines, emissions achieved will be lower along with a reduced fuel cost. This helps preventing production of greenhouse gases. These greenhouse gases when escaped into the atmosphere, trap the sun's radiation and this causes earth to warm up. This phenomenon is known as Greenhouse effect. In addition to that, biomass has several advantages when compared to fossil fuels, such as a truncated life cycle, extensive distribution of source and less emission of greenhouse gas. India has a high range of cultivation of crops and produces considerable amount of agricultural wastes and forestry residues every year, which can be utilised in producing oils and gas which can be used as fuels, lubricants, cooking gas (gobar gas) etc. Nowadays biofuels are given more significance because they have several advantages over the fossil fuels like cost, easily available source, renewability, free of pollution, recycling of waste etc. Despite of having many positive characteristics they have a few limitations such as higher cost, lower energy output and excessive water usage. But as the technology is advancing day-by-day, these limitations can be minimised. As many forms of biomass are available the biofuel can be extracted from various kinds of plants and seeds like Jatropha seed, Sunflower seed, Mahua tree, Lemon peel, Crofton seed etc.

In this research, the biofuels and dual engines are both combined along with oxygen to get prominent results in order to reduce atmospheric pollution.

\subsection{Pyrolysis}

Pyrolysis is a thermo chemical process of breakdown of complex carboneous matter to simple matter in the absence of oxygen. Biomass can be converted to useful gas or a fuel by several types of methods like combustion, fermentation, gasification, pyrolysis etc. Among these methods, pyrolysis is promising and the most flexible technology to industrial applications and is easy to handle and cheaper than other processes. Different types of pyrolysis are; fast and slow. Slow pyrolysis utilizes low temperature around $400^{\circ} \mathrm{C}$ and char is the primary product. Fast pyrolysis utilizes high temperature around $650-1000^{\circ} \mathrm{C}$ and primarily produces gas or liquid. Some of the pyrolysis parameters to be considered for the process includes type of biomass, pyrolysis temperature, catalyst used, and particle size Reactor dimensions, heating rate.

\section{LITERATURE REVIEW}

K.Venkatesan studied the performance of diesel engine using mosambi peel pyro oil with a nanoparticle as a fuel additive. 
This paper examined the emissions and it has been observed that there is a reduction in $\mathrm{NO}_{\mathrm{x}}$ emissions upto $34 \%$ and $\mathrm{HC}$ emissions upto $40 \%$ and that the efficiency has been improved. But from a 2018 study, it was found that incorporating nanoparticles $\left(\mathrm{Al}_{2} \mathrm{O}_{3}\right)$ into Jojoba biodiesel-diesel fuel had improved engine performance and there is a reduction in $\mathrm{NO}_{\mathrm{x}}$ emissions by $70 \%$, carbon monoxide (CO) emissions by $80 \%$ and smoke opacity by $35 \%$. Nano particles if blended with fuel, tend to emit some emissions which are harmful to both environment and to the health of a human being and they may increase combustion to a very high rate which leads to tendency of knock in the engine.

SenthilKumar studied the performance of CI engine using Mahua oil as the fuel with varying amounts of oxygen and compared the results with that of neat diesel fuel. It was found that BTE had improved up to $30.8 \%$ and $\mathrm{HC}$, CO emissions were lowered significantly compared to that of neat diesel fuel. $\mathrm{But} \mathrm{NO}_{\mathrm{x}}$ emissions were increased. In order to reduce them, injection of water or emulsification techniques was used.

Hui Liu et al, has researched on the concept of Dual-fuel Spark Ignition (DFSI) combustion to help increase the BTE and to extend the knock limit. An experiment was carried out when an oxygenated fuel which has large latent of heat and octane number is injected and alcohol-gasoline DFSI combustion was investigated with varying amounts of alcohol percentage. After comparing with different fuel mixtures like Methanol+Gasoline, Ethanol +Gasoline, 15\%water $+85 \%$ ethanol \& Gasoline, the experimental results indicate that Alcohols-gasoline DFSI under the influence of stoichiometric fuel mixture can extend the limit of knock and capably improves the fuel economy whereas methanol and gasoline would exhibit better anti-knock performance and gives high fuel efficiency.

Mohsen M. Abdelaalet al, has done an experimental study using a single-cylinder DI (direct injection) diesel engine which runs on dual-fuel mode with natural gas as a main fuel and diesel fuel as a pilot with variable amounts of oxygen at all engine loads. Comparing the results to that of diesel engine, it is observed that the effect of adding oxygen causes about 7\% reduction in the Brake Specific Energy Consumption (BSEC), increase of Cylinder peak pressure to about

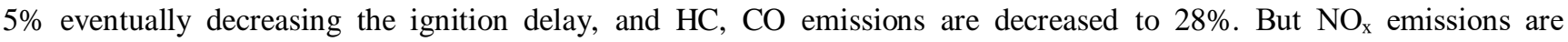
increased four times than that of diesel engine. High oxygen-enrichment at high load conditions may lead to almost zero soot.

A Study on formation and influence factors of $\mathrm{NO}_{\mathrm{x}}$ was carried out by Anren Yao et al, where a simulation of Diesel/methanol dual fuel was used and the effect of Methanol substitution proportion (MSP), Exhaust Gas Recirculation (EGR) and exhaust back pressure on $\mathrm{NO}_{2}$ were analysed. The results when compared with that of diesel engine justified that with methanol in premixed region, there is an increase of $\mathrm{NO}_{2}$. With the increase of MSP, there is an increment at first then a decrement in $\mathrm{NO}_{2}$. The addition of EGR causes a reduction in $\mathrm{NO}_{2}$, and the slight increase of exhaust backpressure would cause total nitrogen oxides emissions to increase.

H.S. Tira et. al has carried out an experiment on a single cylinder DI engine using Liquefied Petroleum Gas (LPG)/Diesel to analyse the impact of properties like Rapeseed Methyl Ester (RME) and Gas-to-Liquid (GTL) on combustion and emission characteristics.According to the results, LPG-RME can be the better alternative fuel because of better combustion variability and reduced $\mathrm{HC}, \mathrm{CO}$, Soot emissions and in LPG-GTL, there is highest amount of $\mathrm{NO}_{\mathrm{x}}$ emission formation due to high Cetane number. EGR can be used to lower the $\mathrm{NO}_{\mathrm{x}}$ emissions.

Bahman Najafi et. al, a study was carried out on a diesel engine running in dual fuel mode with natural gas and a novel fuel mixture of biodiesel and glycerol triacetate additive to examine the effect on engine emissions. The experiment 
was carried out in two modes; dual fuel mode and diesel mode. The results were then compared. The main aim was to reduce the engine emissions as much as possible Based on the experimental results, $\mathrm{NO}_{\mathrm{x}}$ and $\mathrm{CO}$ emissions were reduced up to $63 \%$ and $42 \%$ respectively. Unburned Hydro Carbon emissions were affected negatively and particulate matter emissions were comparatively lower in dual fuel mode than that of in diesel mode.

N. O' Connell et. al has conducted an experimental analysis on a dual fuel engine operating with Biomethane and $50 \%$ PODE (polyoxymethylenedimethylethers) $+50 \%$ Neat diesel to investigate their effects on engine performance, combustion and emissions. The experimental results, after being compared to that of neat diesel fuel operation showed that higher peak pressure, shorter ignition delay, shorter combustion duration and higher BTE were achieved. CO emissions were reduced by $50 \%$ and also $\mathrm{PM}$ and $\mathrm{HC}$ emissions were reduced. $\mathrm{NO}_{\mathrm{x}}$ emissions were increased by $45 \%$. Overall, the PODE blend has a positive effect on the engine performance and combustion parameters.

Harmanpreet Singh et al, has conducted an experiment on a dual fuel CI engine using producer gas which was obtained from sugarcane bagasse \& carpenter waste and Diesel to examine the performance, emission \& noise characteristics of the engine. The engine was tested at six different loads $2 \mathrm{~kg}$ to $12 \mathrm{~kg}$ and run on diesel mode and diesel +producer gas mode. The results exhibited that BSFC, BTE, and Brake power were reduced up to $45.7 \%, 24.5 \%$ and $16.67 \%$ respectively. The level of $\mathrm{NO}_{\mathrm{x}}$ emissions were declined to $69.5 \%$. In dual fuel mode, Noise increases to about $3.4 \mathrm{~dB}$ times the diesel mode.

Experimental evaluation of rice bran bio diesel was effectuated by Bhaskor J. Bora et. al to study the influence of compression ratio on the performance, emission and combustion of a dual fuel engine.The experiment was conducted on a single cylinder, DI, diesel engine run in dual fuel mode using diesel and rice bran bio diesel at different compression ratios which were 18, 17.5 and 17. The results exhibited that there was a reduction in carbon monoxide and hydrocarbon emissions by $17.67 \%$ and $17.18 \%$ respectively and that there was an increase of $\mathrm{NO}_{x}$ andCO $\mathrm{O}_{2}$ emissions by $42.85 \%$ and $14.13 \%$ respectively.

M.Mohamed Musthafa has conducted an experimental study on a partially stabilised zirconia coated single cylinder four stroke DI engine using Liquefied Petroleum Gas (LPG) and Biodiesel both with and without Di-Tertiary Butyl Peroxide (DTBP) as a fuel additive to analyse the engine performance and emissions. Biodiesel was obtained by transesterification of palm oil. After comparing the results obtained of with and without the additive, it can be seen that with the additive, the efficiency was improved by $4.5 \%$ and BSFC was decreased by $4.2 \%$, $\mathrm{HC}$ and CO emissions were reduced from $9 \%$ to $12 \%$ when compared to that of an uncoated diesel engine. $\mathrm{NO}_{\mathrm{x}}$ emissions reduced up to $32 \%$ and EGT also was lowered when fuel additive was added.

Carolina Monteiro Santos et. al, has studied the application of pyrolysed orange peel waste in the production of biofuels and bio-sorbents. The composition of the dried peel was recorded i.e., carbon (44-62\%), oxygen (30-47\%), hydrogen (3-6\%), nitrogen (1-2.6\%), sulphur (0.4-0.8\%). The obtained pyrolysed orange peel was analysed through X-ray fluorescence and CHN analysis, FTIR analysis, Thermal analysis and Biosorption capacity. Through FTIR analysis, it was detected that the sample was in spectrum range of 4000-400 cm-1 with $8 \mathrm{~cm}-1$ spectral resolution. Biosorption analysis was carried out to test the adsorption capacity of the sample in individual solutions of cadmium, aluminium, zinc, copper, nickel, lead to test the sample if it can be used in any removal techniques. Thermal analysis was carried out by taking the sample on alumina crucibles with air or nitrogen and heating it to from $20^{\circ} \mathrm{C}$ to $800^{\circ} \mathrm{C}$. Based on the results obtained, it was observed that calorific value increases with an increase of the pyrolysis temperature. 
Pankaj Dubey et. al, has investigated on the influence of Jatropha biodiesel oil and turpentine oil on the performance, combustion and exhaust emissions of a single cylinder diesel engine with variable compression ratio in dual fuel mode. The experimental procedure was initiated by using fuels of 100\% Jatropha bio-diesel (JB), 90\% Jatropha biodiesel $+10 \%$ Turpentine oil (JBT90), 70\% Jatropha bio-diesel + 30\% Turpentine oil (JBT70), 50\% of Jatropha bio-diesel + $50 \%$ Turpentine oil (JBT50) and diesel. Among these different fuel blends, dual biodiesel blend (JBT50) was the best fuel blend of them. The experimental results achieved were that of the fuel blend JBT 50. BTE increases by $2.17 \%$ while the exhaust emissions $\mathrm{CO}, \mathrm{HC}, \mathrm{NO}_{\mathrm{x}}$ and Smoke were reduced by $13.04 \%, 17.5 \%, 4.21 \%$ and $30.8 \%$ when compared to that of a standard diesel engine operation.

Venkatesan Kuppusamy et. al has analysed the performance and emission characteristics of a four stroke DI engine using cashew nut shell pyro oil with waste cooking oil and diesel. The experiment was carried out using the fuel blends 5\% Cashew pyro oil+5\% Waste cooking oil +90 Diesel, $10 \%$ Cashew pyro oil $+5 \%$ Waste cooking oil $+85 \%$ Diesel and 15\% Cashew pyro oil $+5 \%$ Waste cooking oil $+80 \%$ Diesel and tested at different loads. The results showed that the $\mathrm{HC}$ and $\mathrm{CO}$ emissions were higher and $\mathrm{NO}_{\mathrm{x}}$ and Smoke emissions were reduced to some extent and Brake thermal efficiency decreased compared to that of Bio diesel.

K.Venkatesan et Al. has evaluated the performance and emissions of a CI diesel engine using Mosambi Peel Pyro oil blended with varying concentrations of copper oxide nanoparticles and from the experimental results, it was observed that Brake thermal efficiency increased to $31 \%$ while for diesel it was $30.5 \%$ only and $\mathrm{HC}$, CO, Smoke were decreased to about $7.6 \%, 7.96 \%$ and $20 \%$ respectively and $\mathrm{NO}_{\mathrm{x}}$ increased to $20 \%$ compared to that of neat diesel operation.

P. Premakumar et Al. has studied the performance and emissions of a CI diesel engine using Mosambi peel pyro oil blended with Methyl ester. The experimental results revealed that $\mathrm{NO}_{\mathrm{x}}$ emissions have risen up to $8.7 \%$, Smoke, $\mathrm{HC}$, CO emissions have fallen to $20 \%, 10.9 \%$ and $30.77 \%$ relative to the diesel characteristics. Due to high viscosity of the fuel blends, Brake specific fuel consumption has increased compared to that of diesel.

K.Venkatesan assessed the performance and emission parameters of a CI, diesel engine using Mosambi peel pyro oil with methanol blended. Different fuel blends were tested and the results found to be that Brake thermal efficiency has increased by $1.64 \%$, Smoke and $\mathrm{NO}_{\mathrm{x}}$ decreased by $20 \%$ and $11.1 \%$ when compared to diesel operation. $\mathrm{HC}$ and $\mathrm{CO}$ emissions increased outstandingly due to the presence of methanol.

Y.V.Hanumantha Rao et Al. has investigated the effect of fuel injection pressure on the performance and emissions using linseed oil blended with diesel. When the fuel injection pressure was increased from 200 bar to 240 bar, the results exhibited that Brake specific energy consumption decreased, Mechanical efficiency and Brake thermal efficiency increased, $\mathrm{CO} \& \mathrm{CO}_{2}$ emissions increased drastically.

An experimental investigation on CI engine fuelled with Mahua oil methyl esters was conducted by K. Srinivasa Reddy et al. The experiment was carried through with different blends like B5, B10, B20, B30. From the achieved results, it was shown that Brake specific consumption and indicated thermal efficiency have decreased, Mechanical efficiency slightly increased.

Y.V. Hanumantha Rao et al. conducted an experimental investigation on the performance of a single cylinder diesel engine using Tobacco-Diesel blends. The results exhibited that the Brake specific fuel consumption has decreased up to $9.62 \%$ and Brake thermal efficiency increased up to $20 \%$ when compared to that of diesel fuel. Smoke emissions 
decremented tremendously. Hence, these fuel blends can be used as alternative fuels.

\section{MATERIALS AND METHODOLOGY}

\subsection{Source of Mosambi Peel oil}

The biomass which is readily available for pyro oil production in India is procured from plant species such as Jatropha (Jatropha curcas), Mosambi (Citrus limetta) and Tamanu (Calophylluminophyllum), Mahua tree (Madhucalongifolia), cotton seed (Gossypium) etc. Mosambi plants are naturally distributed along the coasts and river banks in India and also in humid tropical lands.

The peels of Mosambi were washed and shredded into tiny pieces and dried at $110{ }^{\circ} \mathrm{C}$ for three days. After the peels were dried completely, they were made into a powder and oil was extracted.The raw mosambi peel pyrolyzed oil was analysed to evaluate the chemical composition and physical properties. The peel of Mosambi has high amount of crude fibre, water and capacity to hold oils. The extracted Mosambi peel pyro oil has a high advantage of having higher Cetane number, oxygen content and it is clean for a fuel.

The oil yielded from the peels of a certain amount of mosambi can be calculated as below

Oil yield $\%=\frac{\text { (mass of mosambi peels })}{\text { (mass of oil extracted })}=100$

\subsection{Property Analysis}

The process fast pyrolysis of a biomass produces a liquid product. The mosambi peel pyro oil contains a very low amount of ash and a high volumetric density than the actual biomass which is the mosambi peel. The colour of the pyro oil is a reddish brown with a strong odour. Since the pyro oil contains a large number of oxygenated components, it does not mix easily with hydrocarbons. Also, the pyro oil has a low $\mathrm{pH}$ value of around 3 and can be stored for more than a year.

The table below shows the composition of the dried peel of Mosambi and the pyrolysed product which is majorly biochar.

Table 1

\begin{tabular}{|l|c|c|c|}
\hline $\begin{array}{c}\text { Elemental } \\
\text { composition (wt\%) }\end{array}$ & Dried Peel & BC 250 ${ }^{\circ} \mathbf{C}$ & $\mathbf{B C ~}^{450}{ }^{\circ} \mathbf{C}$ \\
\hline $\mathrm{C}$ & 44.5 & 53.3 & 62.1 \\
\hline $\mathrm{O}$ & 47.3 & 39.4 & 30.9 \\
\hline $\mathrm{N}$ & 1.5 & 1.9 & 2.4 \\
\hline $\mathrm{H}$ & 6.1 & 4.8 & 3.6 \\
\hline $\mathrm{S}$ & 0.4 & 0.3 & 0.8 \\
\hline Ash content & 4 & 5 & 7.8 \\
\hline
\end{tabular}

Properties like Kinematic viscosity, Fire point, Flash point, Density, Latent heat of vaporization were calculated and recorded for further research purpose. These physical properties enable to predict the nature of the fuel when blended with diesel. Some changes can cause explosions so as to prevent the properties and blends of the mosambi peel pyro oil are found out. The data recorded is given in the table below: Table 2 
Table 2

\begin{tabular}{|l|c|c|c|}
\hline \multicolumn{1}{|c|}{ Properties } & Diesel & $\begin{array}{c}\text { Raw mosambi peel } \\
\text { pyro oil }\end{array}$ & $\begin{array}{c}\text { 90\% Diesel+10\% Mosambi } \\
\text { peel pyro oil }\end{array}$ \\
\hline Kinematic viscosity @ $40^{\circ} \mathrm{C}(\mathrm{cst})$ & 3.2 & 2.6 & 3.4 \\
\hline Density $\left(\mathrm{kg} / \mathrm{m}^{3}\right) @ 15^{\circ} \mathrm{C}$ & 842 & 880 & 846 \\
\hline Latent heat of vaporisation $(\mathrm{kJ} / \mathrm{kg})$ & 265 & 279 & 270 \\
\hline Calorific value $(\mathrm{kJ} / \mathrm{kg})$ & 43,200 & 37,560 & 39,500 \\
\hline Cetane number & 45 & 48 & 46 \\
\hline Fire point $\left({ }^{\circ} \mathrm{C}\right)$ & 55 & 65 & 58 \\
\hline Flash point $\left({ }^{\circ} \mathrm{C}\right)$ & 50 & 59 & 53 \\
\hline Self-Ignition Temperature $\left({ }^{\circ} \mathrm{C}\right)$ & 260 & 243 & 254 \\
\hline $\mathrm{p}_{\mathrm{H}}$ value & 5.6 & 3.9 & 4.2 \\
\hline
\end{tabular}

\subsection{FTIR Analysis}

Fourier Transformed Infrared Spectroscopy (FTIR) analysis was executed on the dried peels of mosambi. The dried powder of mosambi peel was compressed onto a $1 \mathrm{~mm}$ pellet for the measurement in the frequency range $4000-400 \mathrm{~cm}^{-1}$. The FTIR analysis result identifies the classified functional group compounds and bonding types. From the result, the sample exhibited 3351, 2917, 1741, 1683, 1604, 1400, 1054 and $609 \mathrm{~cm}-1$ peaks corresponding to alcohols $(\mathrm{O}-\mathrm{H})$, carboxylic acids (stretching), aldehydes\& ketones $(\mathrm{C}=\mathrm{O})$, alkenes $(\mathrm{C}=\mathrm{C})$, alcohols, ethers \& esters $(\mathrm{C}-\mathrm{O})$, primary alcohol (C-O stretching), alcohol (O-H bending ) respectively.

\subsection{Blending Test Analysis}

Different fuel blends are tested out so that the emissions can be lowered and the specific and economical requirements are satisfied. Primary alcohols like Methanol, Ethanol etc. can be used as fuel blends, but they very much effect the HC, CO and $\mathrm{NO}_{\mathrm{x}}$ emissions which isn't convenient for the atmosphere. Nano additives can be used as fuel blends which produce better combustion stability, fast oxidation, lower melting point etc. and improve Brake Thermal Efficiency, but they have low specific heat which would weaken the combustion rate and they are of high cost. The derived Mosambi peel pyro oil is blended with oxygen so as to reduce the $\mathrm{NO}_{\mathrm{x}}$ emissions and to enhance the combustion and efficiency of the dual fuel engine. The fuel blends used in this experiment are 90\% Diesel $+10 \%$ Mosambi Peel Pyro Oil, 90\% Diesel $+10 \%$ Mosambi Peel Pyro Oil $+21 \%$ Oxygen, 90\% Diesel $+10 \%$ Mosambi Peel Pyro Oil $+22 \%$ Oxygen \& 90\% Diesel $+10 \%$ Mosambi Peel Pyro Oil $+23 \%$ Oxygen .

\subsection{Uncertainty Analysis}

As variety of instruments was being used in the experiment, their accuracy levels differ for every instrument. The accuracies established were calculated by uncertainty analysis. In every investigation/experiment there occur errors and uncertainties which might be caused by humans, environmental changes etc. The uncertainties recorded were tabulated as shown below:

Table 3

\begin{tabular}{|c|l|c|}
\hline Sl. No & \multicolumn{1}{|c|}{ Parameters } & Percentage of Uncertainty \\
\hline 1 & Brake Specific Fuel Consumption & $0.4 \%$ \\
\hline 2 & Brake Thermal Efficiency & $0.5 \%$ \\
\hline 3 & $\mathrm{NO}_{\mathrm{x}}$ & $1.5 \%$ \\
\hline 4 & $\mathrm{HC}$ & $1.2 \%$ \\
\hline 5 & $\mathrm{CO}$ & $0.7 \%$ \\
\hline 6 & Smoke & $1.4 \%$ \\
\hline
\end{tabular}




\section{Experimental Setup}

The setup [fig1] \& [Table 3] consists of a test engine which is a single cylinder, four-stroke, air cooled, Direct Injection, CI engine in dual fuel mode. An oxygen tank is connected to the setup for the supply of oxygen which was compressed and stored at 150bar in the tank. It is provided a valve and a flow meter to control the flow rate of oxygen. A flame trap arrangement is provided which is a safety device to put out the backfire coming from the engine. This prevents explosions in the engine. In the experiment, the injection timing was set to $27^{\circ}$ before TDC position of the piston. Emission analysers for detecting different types of emissions are connected to the exhaust manifold of the test engine. The data from the emission analysers is recorded with the help of a computer which is connected to the analysers. Exhaust Gas Temperature can be recorded using thermocouples. For each load, the filters of the emission analyser were changed. Engine was tested at various loads of brake power.

Table 4

\begin{tabular}{|l|l|}
\hline \multicolumn{1}{|c|}{ Engine Type } & \multicolumn{1}{c|}{$\begin{array}{c}\text { Single Cylinder, Four-Stroke, Air-Cooled } \\
\text { Direct Injection Dual Fuel Engine }\end{array}$} \\
\hline Injection Timing & $27^{0}$ BTDC \\
\hline Injection Pressure & $210 \mathrm{bar}$ \\
\hline Compression Ratio & $17.5: 1$ \\
\hline Displacement Volume & $661 \mathrm{cc}$ \\
\hline Bore and Stroke & $87.5 \times 110 \mathrm{~mm}$ \\
\hline Fuel Injection Time & $27^{0}$ BTDC \\
\hline Injection System & Mechanical Pump \\
\hline Combustion Chamber type & Hemi-spherical type \\
\hline Speed & $1500 \mathrm{rpm}$ \\
\hline Rated Power & $5.2 \mathrm{~kW}$ \\
\hline Dynamometer Type & Eddy current \\
\hline
\end{tabular}

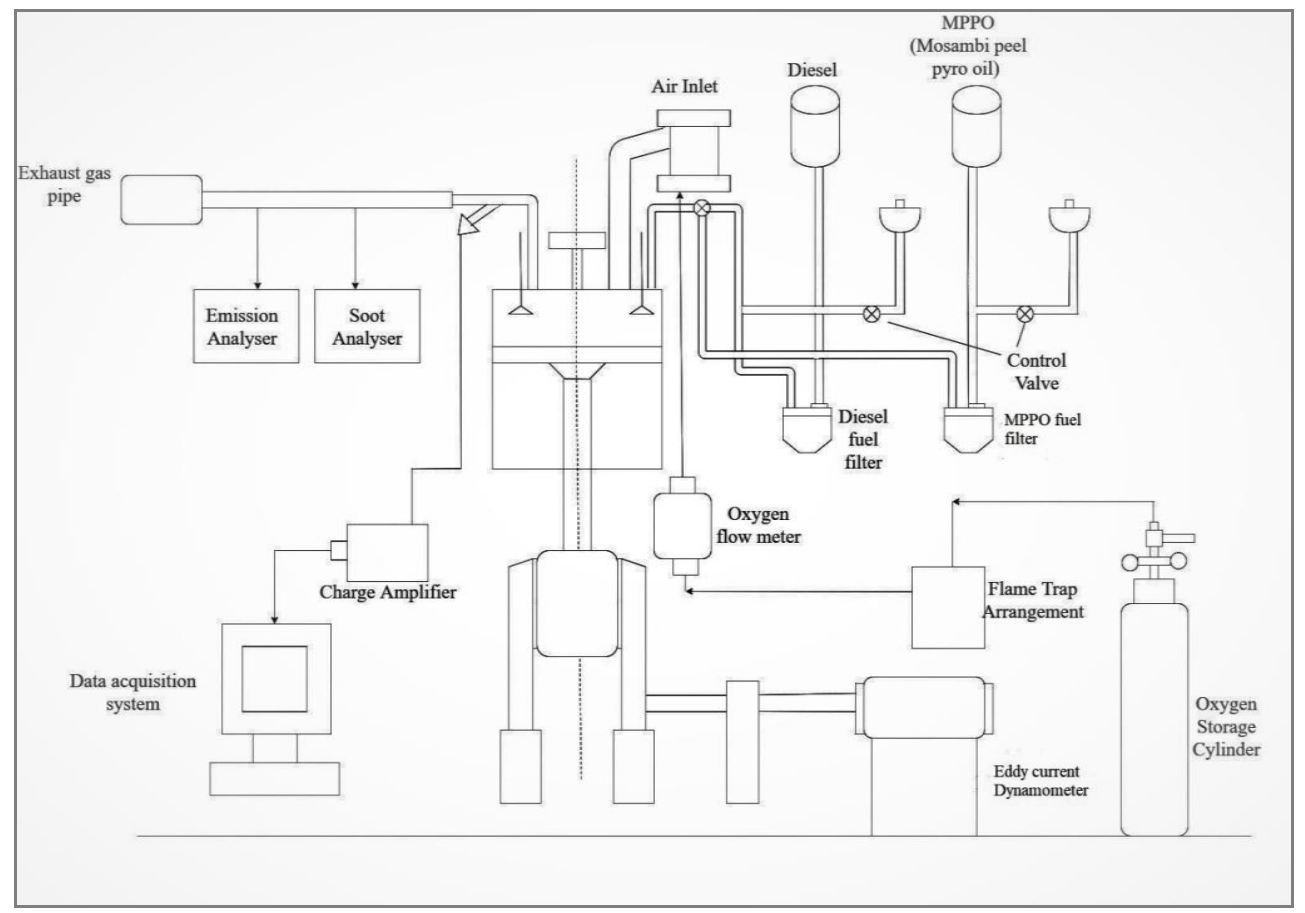

Figure 1: Block Diagram of the Test Engine Setup 


\section{RESULTS AND DISCUSSIONS}

\subsection{Engine Performance Analysis}

\section{Brake Thermal Efficiency}

Brake Thermal efficiency of an engine is the efficiency with which the fuel is converted from chemical energy to mechanical energy. BTE is calculated by the formula

$$
B T E=\frac{B P}{(T F C * C V)} \%
$$

where BP is Brake Power $(\mathrm{kW})$

TFC is Total Fuel Consumption $(\mathrm{kg} / \mathrm{hr})$

$\mathrm{CV}$ is Calorific Value $(\mathrm{kJ} / \mathrm{kg})$

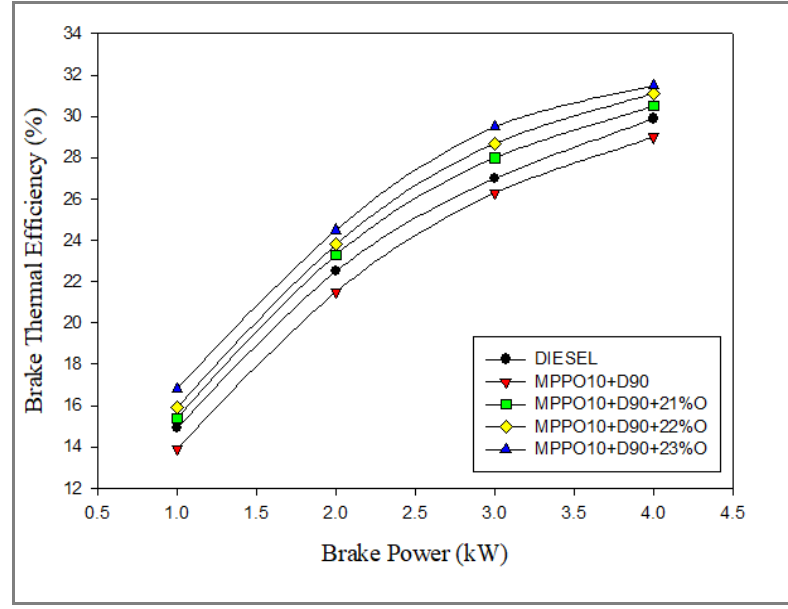

Figure 1: Brake Thermal Efficiency vs. Brake Power

From the graph, it was observed that Brake Thermal Efficiency of the fuel blend MPPO10+D90+23\% Oxygen has increased by 5.35\% more than that of Diesel fuel. The oxygen enrichment results in a complete combustion causing an improvement in BTE.

\section{Brake Specific Fuel Consumption}

Brake Specific Fuel Consumption is defined as the quantity of fuel consumed by the test engine to develop unit kilowatt of power output. From the graph, it was observed that when compared to that of Diesel fuel, there occurs a decrease of $27.03 \%$ in BSFC for the fuel blend MPPO10+D90+23\% Oxygen. Hence the oxygen enrichment instigates the air- fuel mixtureto form a sustainable flame therefore resulting in a better fuel economy. If the combustion stability is adequate enough then ignition delay decreases and therefore promoting BTE. 


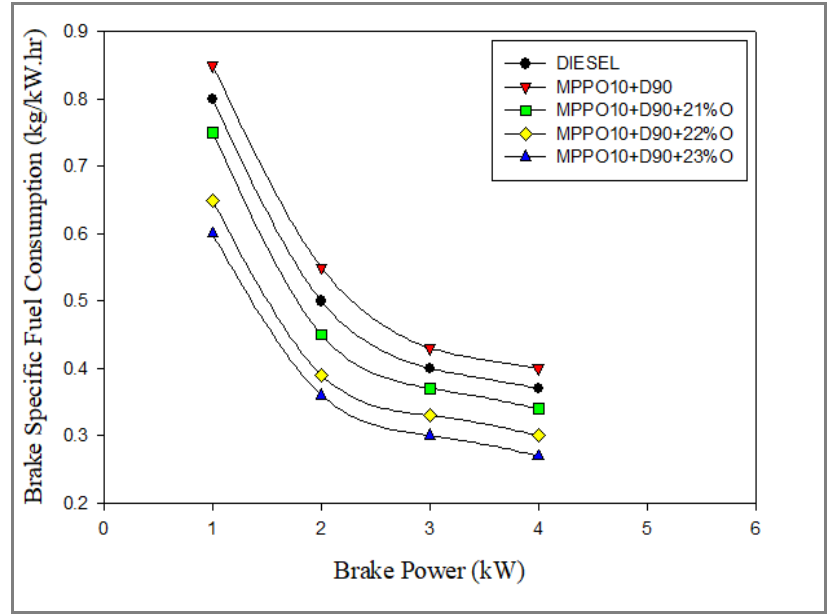

Figure 2: Brake Specific Fuel Consumption vs. Brake Power

\section{Exhaust Gas Temperature}

An increase in EGT is due to advanced heat release which occurs due to rapid combustion and high flame velocity. This may often cause for the tendency of knock. It was observed from the graphs that there is a decrease of $13.91 \%$ in MPPO fuel blend with 23\% Oxygen when compared to Diesel fuel. Longer combustion duration can be the cause for high EGT for the fuel blend MPPO10+D90. Oxygen enrichment therefore reduces EGT and helps to complete combustion appropriately.

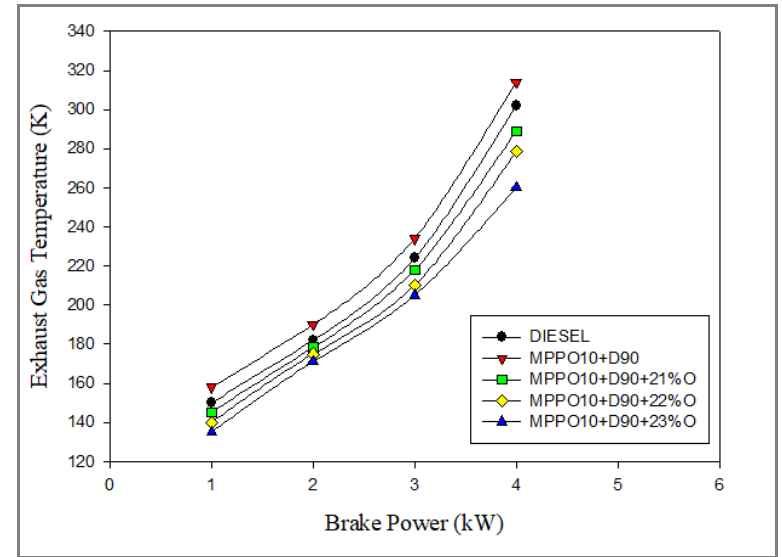

Figure 3: Exhaust Gas Temperature vs. Brake Power

\section{Engine Emission Analysis}

\section{Smoke}

Smoke opacity of the exhaust gas is applicable for measuring the PM (particulate matter) emitted. The graph exhibits Smoke opacity of the test fuel blends and Diesel. It can be seen that for 10\%MPPO\&90\% Diesel fuel with 23\% Oxygen the smoke opacity was decremented by $17.94 \%$ to that of Diesel fuel. This reduction is due to the speedy evaporation of fuel and shorter ignition delay caused by oxygen enrichment. Furthermore, the high oxygen concentration at high loads of engine could lead to almost zero soot. The only drawback is that excess $\mathrm{NO}_{\mathrm{x}}$ emissions would be emitted. 


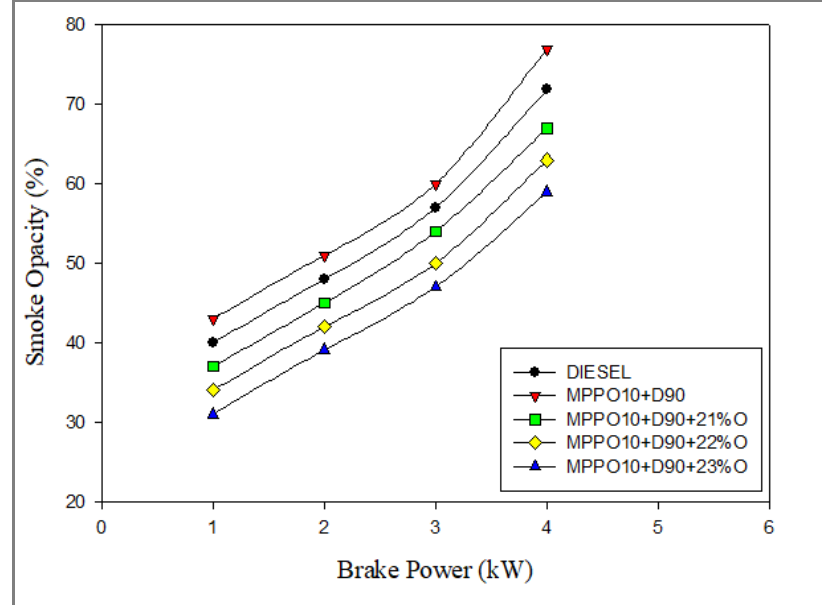

Figure 4: Smoke Opacity vs. Brake Power

\section{$\mathrm{NO}_{\mathrm{x}}$}

From the graph below, it was found that the $\mathrm{NO}_{\mathrm{x}}$ increased by $5.63 \%$ for the fuel MPPO10+D90+23\% Oxygen than that of Diesel fuel. NO emissions form mostly in the peak temperature regions of the combustion chamber. Thermal $\mathrm{NO}_{\mathrm{x}}$ mainly depends on temperature rate and oxygen concentration. Due to the intense flame propagation caused by an unprompted ignition which leads to the rise of cylinder peak pressure. Therefore, this causes an increment in $\mathrm{NO}_{\mathrm{x}}$ emissions. Prompt $\mathrm{NO}_{\mathrm{x}}$ forms due to the advanced injection of the fuel which leads to chemical reactions in the pre-ignition stage. Hence, incomplete combustion products and active radicals were attained throughout the compression stroke of the engine cylinder.

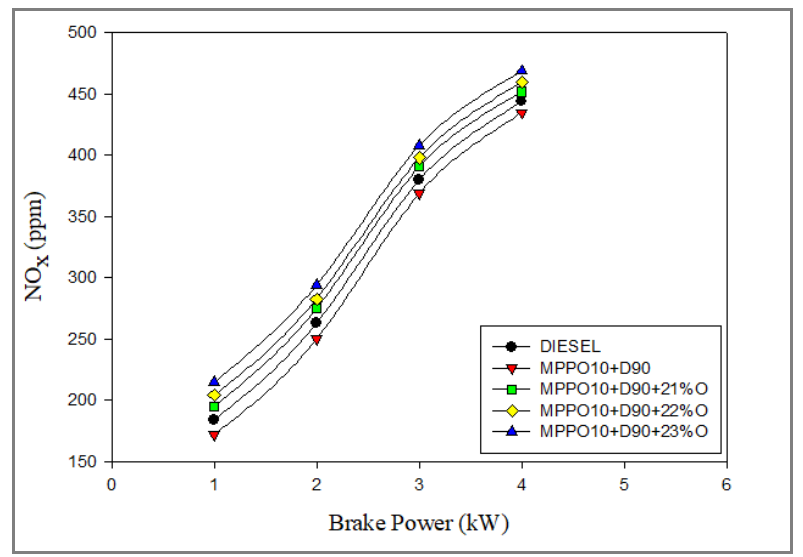

Figure 5: $\mathrm{NO}_{\mathrm{x}}$ vs. Brake Power

\section{HC}

From the graph, it can be seen that HC (ppm) emission has decrement of about $14.61 \%$ after being compared to Diesel. Sometimes, when the air-fuel mixture is lean, it would result in misfiring and unstable combustion. And quenching may also occur due to reduced peak-in pressure. Hence, Oxygen enrichment improves flame propagation resulting in a stable combustion which would also cause the cylinder peak-in pressure to increase. Utilising mosambi peel pyro oil causes a major reduction of $\mathrm{HC}$ emissions because of fast oxidation rate and a brisk combustion of fuel. 


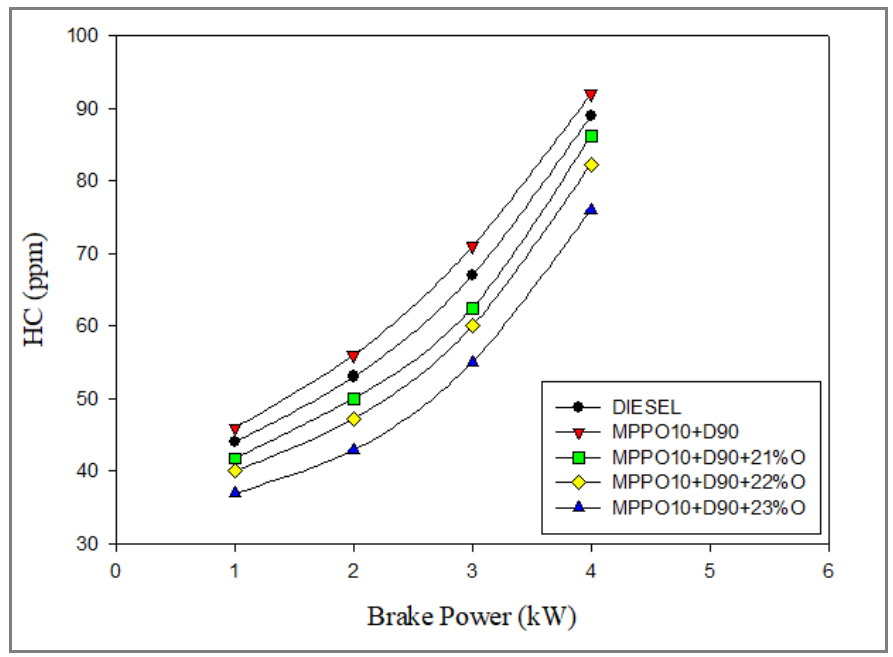

Figure 6: HC vs. Brake Power

\section{CO}

The graph shows that the CO \% of MPPO with 23\% Oxygen enrichment decreased up to 47.98\% compared to Diesel. The highest percentage of CO is seen in fuel 10MPPO+D90 which is without any Oxygen content. The oxygen present in the fuel causes unwanted fuel stagnation on the walls of the cylinder. This would result in preventing the air-fuel mixture from becoming leaner. As a consequence, the $\mathrm{CO}$ emissions decline to a significant level.

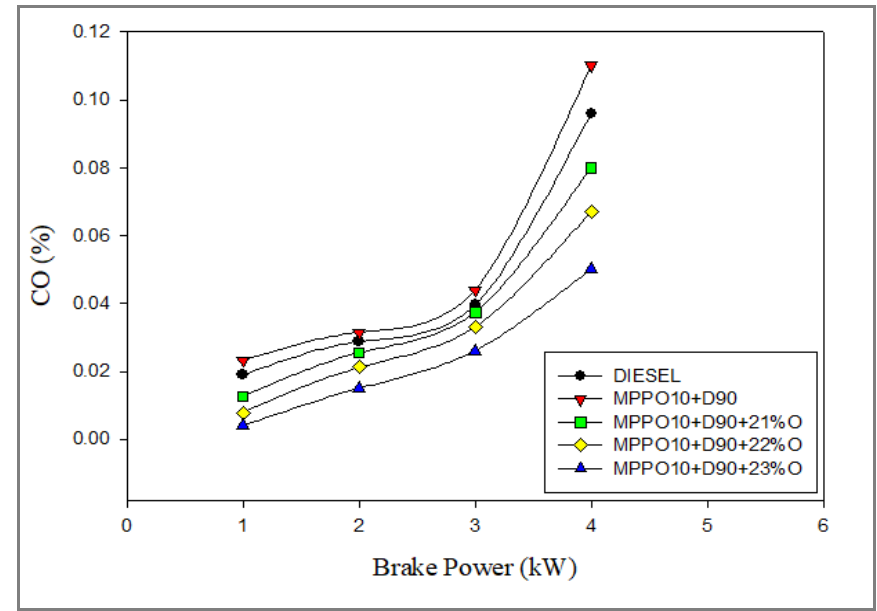

Figure 7: CO vs. Brake Power

\section{Combustion Analysis}

\section{Ignition Delay}

Ignition Delay of an engine is the time interval between the start of injection of the fuel and the start of combustion. The graph displays that for 10MPPO+90D+23\% Oxygen, ignition delay decreases for about $7.5 \%$ to that of Diesel. As the oxygen present in the mosambi peel pyro oil causing the lowering of heat dissipation results in an early combustion thereby degrading the ignition delay. The higher the amount of oxygen enrichment, the shorter the ignition delay can be achieved. 


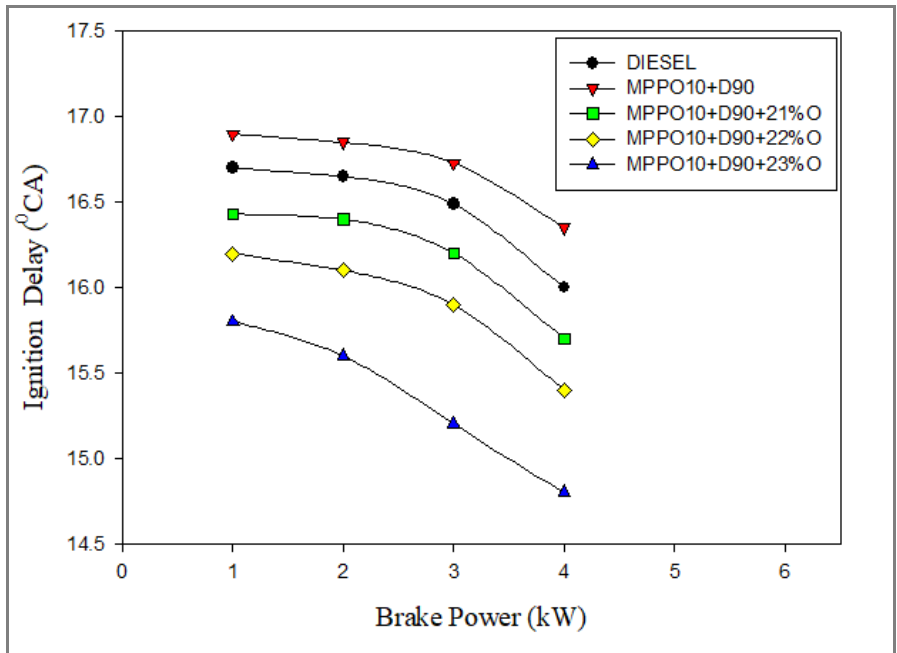

Figure 8: Ignition Delay vs. Brake Power

\section{Combustion Duration}

Combustion duration is defined as the crank angle interval between the initiations of combustion and the crank angle where combustion was completed approximately by $99 \%$. Due to the rapid combustion rate, combustion duration could be depreciated. From the graph, it can be observed that a decrement of $21.23 \%$ occurs in fuel blend with highest percentage of oxygen when compared to Diesel. The oxygen present causes the flame region to intensify and quicker dissolution of fuel thereby resulting in a reduced heat transfer and an improved combustion process.

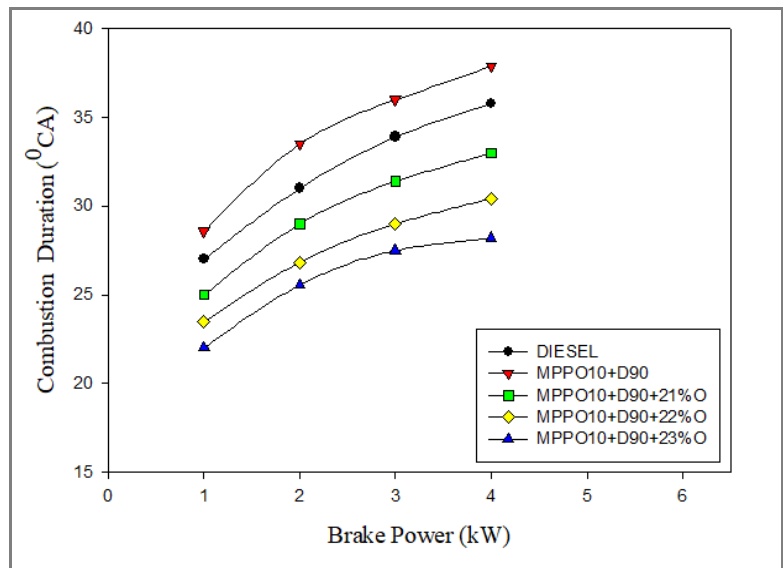

Figure 9: Combustion Duration vs. Brake Power

\section{Cylinder Peak Pressure}

Since the mosambi peel pyro oil has a high Cetane number and an adequate Calorific value, it would result in higher cylinder peak pressure. An increment of $9.92 \%$ in $\mathrm{MPPO}+\mathrm{D} 90+23 \% \mathrm{O}$ can be detected from the graph rather than that of Diesel. As the intake air was replaced by oxygen, it influences the cylinder peak-in pressure to rise which in turn initiates a quicker evaporation of the fuel and simultaneously increasing the energy release rate. The pressure depends mostly on combustion efficiency. The amount of oxygen is directly proportional to cylinder peak pressure. 


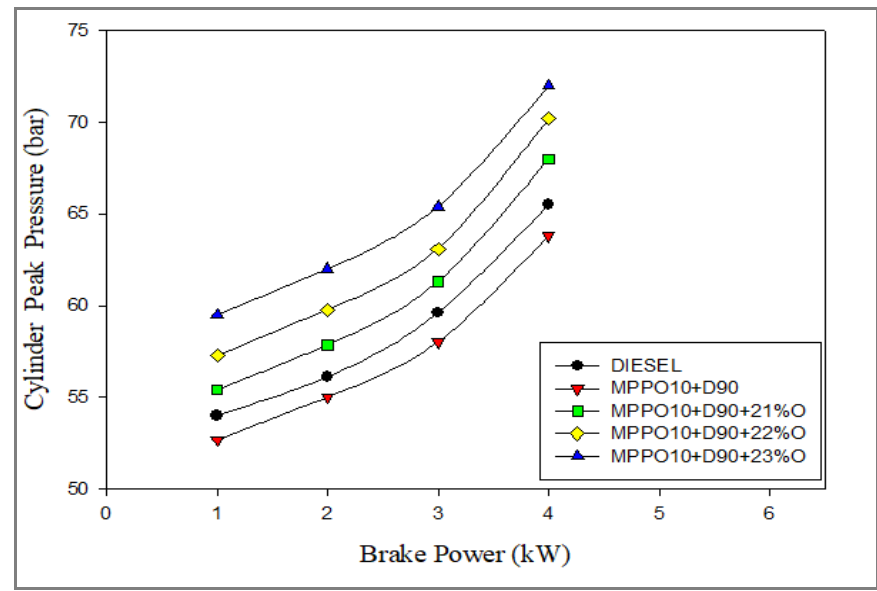

Figure 10: Cylinder Peak Pressure vs. Brake Power

\section{Maximum Rate of Pressure Rise}

An increment of $11.97 \%$ than that of Diesel was seen for the fuel MPPO with $23 \%$ Oxygen. HRR and MROPR depend on each other. The increment can possibly be caused due to increased laminar flame speed.

\section{Heat Release Rate}

The characteristics of heat release exhibit the combustion process and how it effects the combustion stability

The net heat release rate can be calculated by the formula

$$
Q_{\text {net }}=\frac{\gamma}{\gamma-1} p \frac{d V}{d \theta}+\frac{1}{\gamma-1} V \frac{d p}{d \theta}
$$

where $\mathrm{V}$ is the ratio of specific heats, $\mathrm{V}$ is cylinder volume and $\mathrm{p}$ is in-cylinder pressure.

The increase of HRR caused by the low calorific value of mosambi peel pyro oil.

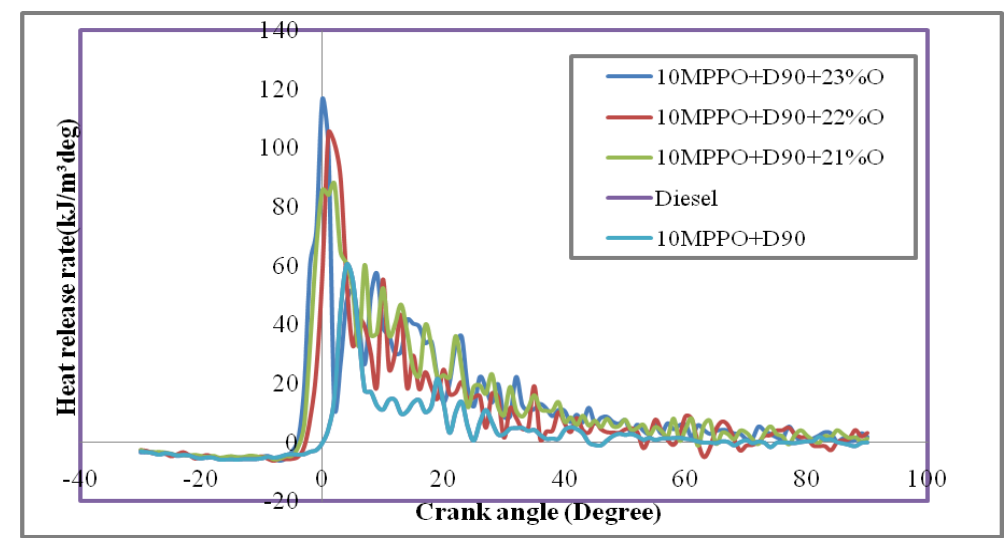

Figure 12: Heat Release Rate vs. Crank Angle

\section{CONCLUSIONS}

Dual fuel engine using mosambi peel pyro oil along with oxygen enrichment might be the most useful and environment friendly engine which can be used in automobiles efficiently. The emission and combustion characteristics were studied by conducting an experiment using mosambi peel pyro oil and diesel in a four-stroke, DI engine run in dual fuel mode with 
varying amounts of oxygen. The physical properties of the pyro oil derived from mosambi peel were analysed, FTIR analysis and blending test have been conducted to know the elemental composition of the pyro oil and to find a better fuel blend.

From the experimental results obtained, it can be depicted that:

- It can be observed that there was an augmentation of 5.35\%, when compared to Diesel mode. Brake Thermal Efficiency was found to be highest in 90\%Diesel+ $10 \%$ mosambi peel pyro oil+ $23 \%$ Oxygen fuel blend.

- BSFC was reduced up to $27.03 \%$ when compared to Diesel fuel operation.

- $\mathrm{HC}, \mathrm{CO}$, Smoke emissions were reduced by $14.61 \%, 47.98 \%$ and $17.94 \%$ respectively.

- The oxygen present in the oil would increase cylinder peak pressure which leads to an increment in $\mathrm{NO}_{\mathrm{x}}$ emissions.

\section{REFERENCES}

1. Venkatesan. K, \& Rao. J, (2018),Diesel engine performance and emission analysis using mosambi peelpyro oil with Nano additive particles,International Journal of Mechanical and Production Engineering Research and Development (IJMPERD),8(6), 311-316, DOI:10.24247/ijmperddec201835.

2. Senthil Kumar. M,(January 2019), The influence of air side and fuel side water addition onengine's behaviour of a biofuel based CI engine under oxygen enriched combustion, Article in Thermal Science, DOI: 10.2298/TSCI171116018M.

3. Liu. H, Wang. Z, Long. Y, \& Wang. J, (2015), Dual-Fuel Spark Ignition (DFSI) combustion fuelled with different alcohols and gasoline for fuel efficiency, Fuel, (April), vol.157, 255-260.https://doi.org/10.1016/j.fuel.2015.04.042

4. Abdelaal. M. M, Rabee. B. A, \&Hegab. A. H, (2013), Effect of adding oxygen to the intake air on a dual-fuel engine performance, emissions, and knock tendency. Energy, 61, 612-620.

5. Wang. B, Yao.A, Chen.C, Yao. C, Wang. H, \& Liu. M, (2019),Strategy of improving fuel consumption and reducing emission at low load in a diesel methanol dual fuel engine. Fuel, 254(92), 115660,https://doi.org/10.1016/j.fuel.2019.115660.

6. Tira. H. S, Herreros. J. M, Tsolakis. A, \&Wyszynski.M. L, (2012), Characteristics of LPG-diesel dual fuelled engine operated with rapeseed methyl ester and gas-to-liquid diesel fuels. Energy, 47(1), 620-629, DOI10.1016/j.energy.2012.09.046.

7. Najafi. B, Akbarian. E, Lashkarpour. S. M, Aghbashlo. M, Ghaziaskar. H. S, \& Tabatabaei. M. (2018), Modelling of a dual fuelled diesel engine operated by a novel fuel containing glycerol triacetate additive and biodiesel with genetic algorithm combined with artificial neural network to reduce engine emissions,Energy, Vol.168, 1128-1137, https://doi.org/10.1016/j.energy.2012.09.046.

8. Lechner. R, Luo. T, \& Brautsch. M,(2019), PODE-blend as pilot fuel in a bio methane dual fuel engine: Experimental analysis of performance, combustion and emissions characteristics. Renewable Energy, Elsevier, vol. 143(C),101-111,DOI: 10.1016/j.renene.2019.04.127.

9. Singh. H, \& Mohapatra.S. K, (2016),Production of producer gas from sugarcane bagasse and carpentry waste and its sustainable use in a dual fuel CI engine: A performance, emission and noise investigation, SC. Journal of the Energy Institute, Vol: 91, Issue: 1, 43-54, https://doi.org/10.1016/j.joei.2016.11.002

10. Bora. B. J, \& Saha.U. K, (2016), Experimental evaluation of a rice bran biodiesel e biogas run dual fuel diesel engine at varying compression ratios, Renewable Energy, 87, 782-790,DOI: 10.1016/j.renene.2015.11.002. 
11. Musthafa. M. M, (2019),A comparative study on coated and uncoated diesel engine performance and emissions running on dual fuel (LPG - biodiesel) with and without additive. IndustrialCrops\&Products ,Vol:128,194-198 https://doi.org/10.1016/j.indcrop.2018.11.012

12. Bhavinkumar N Patel \& Dattatraya Subhedar, "Experimental and Numerical Investigation of Diesel Engine Turbocharger”, International Journal of Automobile Engineering Research and Development (IJAuERD), Vol. 6, Issue 3, pp. 11 - 16

13. Morais. L. C. De, Santos. C. M, Dweck. J, Viotto. R. S, \& Rosa. A. H, (2015), Application of Orange Peel Waste in the Production of Solid Biofuels and Biosorbents $\quad$ Bioresource Technology, 196:469479,DOI:10.1016/j.biortech.2015.07.114.

14. Dubey. P, \& Gupta. R, (2017), Influences of dual bio-fuel (Jatropha biodiesel and Turpentine oil) on single cylinder variable compression ratio diesel engine, Renewable Energy,115(C),1294-1302.https://doi.org/10.1016/j.renene.2017.09.055.

15. Kuppusamy. V, \& Sankerlal. S, (February 2018), Performance and emission characteristics of Cashew nut shell pyrolysed oil - waste cooking oil with diesel fuel, International Journal of Mechanical and Production Engineering Research and Development (IJMPERD),8(1), 181-188, DOI:10.24247/ijmperdfeb201821.

16. Venkatesan. K, \& Sathyaraj. S, (June 2019), Evaluation of CI engine performance and emission fuelled by Diesel-Mosambi peel pyro oil blended with Copper Oxide nanoparticles, International Journal of Mechanical and Production Engineering Research and Development (IJMPERD),9(3), 1-12.

17. R T Naik \& Nilesh Chavan, "Emission Characteristics of a High Speed Diesel Engine”, International Journal of Mechanical Engineering (IJME), Vol. 5, Issue 4, pp. 29-36

18. Venkatesan. K, Kumar, B. K., \& Kumar, P. S. P. (June 2019). Evaluating performance and emissions of CI engine run by blends of Mosambi peel Methyl ester and diesel fuel,International Journal of Mechanical and Production Engineering Research and Development (IJMPERD),9(3), 593-600.

19. Venkatesan. K., \& Rao, J. R. (December 2019). A comprehensive assessment on performance and emissions of CI engine fuelled with diesel and Mosambi peel pyro oil blended with Methanol, International Journal of Mechanical and Production Engineering Research and Development (IJMPERD) ISSN,9, 100-110.

20. N. Durga Prasad Rao, M. V. S. Murali Krishna, B. Anjenaya Prasad \& P. V. K. Murthy, "The Effect of Thermal Barrier Coating on Exhaust Emissions and Combustion Characteristics of Diesel Engine with Rice Brawn Oil Based Biodiesel”, IMPACT: International Journal of Research in Engineering \& Technology (IMPACT: IJRET), Vol. 2, Issue 2, pp. 183-190

21. Theja. A. K, \& Rao Y. V. H, (2016), Investigations on Effect of Fuel Injection Pressure on Performance and Emissions of Linseed Blends in a Diesel Engine,International Journal of Engineering and Technology (IJET), 8(2), 1053-1068.

22. Reddy. K. S, (November 2017), Experimental investigation on performance of compression ignition engine fuelled with Mahua oil Methyl esters,International Journal of Mechanical Engineering and Technology (IJMET),8(11), 147155,http://www.iaeme.com/IJMET/issues.asp? JType=IJMET\&VType $=8 \& I T y p e=1$.

23. Oyetunji O. R\& Hammed B. M, "The Effect of Overall Density on the Mechanical Properties of Flexible Polyurethane Foam", BEST: Journal of Management, Information Technology and Engineering (BEST: JMITE), Vol. 2, Issue 1, pp. 19-32

24. Reddy. K. S, Rao.Y.V.H, (July 2014), Experimental Investigation on the Performance of Single Cylinder Diesel Engine using Tobacco-Diesel Blends, International Journal of Mechanical And Production Engineering (IJMPE),4(2), 268-276.DOI: $10.13140 / R G \cdot 2 \cdot 2 \cdot 32351.56489$ 